\title{
MEDIATING EFFECTS OF EMPLOYEE COMMITMENT IN RELATIONSHIP BETWEEN TOXIC LEADERSHIP AND EMPLOYEES' PERFORMANCE
}

\author{
Muhammad Rahman Khan ${ }^{1 *}$, Hamid Khan ${ }^{2}$, Sajjad Ahmad Jan ${ }^{3}$, Aziz Javad ${ }^{4}$, Aman Ullah Khattak ${ }^{5}$ \\ ${ }^{1 *}$ M. Phil Scholar, Department of Business Administration, Gomal University, Dera Ismail Khan, Pakistan; ${ }^{2}$ Assistant \\ Professor, Institute of Business Administration, Gomal University, Dera Ismail Khan, Pakistan; ${ }^{3} \mathrm{PhD}$ Scholar, Sarhad \\ University of Science and Technology, Peshawar, KP, Pakistan; ${ }^{4,5}$ Assistant Professor, Institute of Business \\ Administration, Gomal University, Dera Ismail Khan, Pakistan. \\ Email: ${ }^{1 *}$ innocent.rocky26@ gmail.com, ${ }^{2}$ hamid.nido@gmail.com, ${ }^{3}$ sajjad.msba@ gmail.com, ${ }^{4}$ azizjaved73@gmail.com, \\ 5 amanu_khattak@hotmail.com
}

Article History: Received on $28^{\text {th }}$ June 2021, Revised on $15^{\text {th }}$ July 2021, Published on $17^{\text {th }}$ July 2021

\begin{abstract}
Purpose of Study: The study aimed to examine the mediating effects of employee commitment in the relationship between toxic leadership and employee performance in the context of the banking sector, KP, Pakistan. The study is expected to provide significant information to existing knowledge databases about the toxic leaders, organizational commitment, and employees' performance.

Methodology of Study: The cross-sectional design was used to conduct the study by using a 5-point Likert scale through the questionnaire to collect primary data from the high-level managers of selected commercial banks located south region of KP, Pakistan. The sample of 234 employees of both public/private sector banks was taken randomly as the sample. To compute sample, Yamane (1967) formula for selecting sample from finite population: $n=$ population (566), level of significance, $e=0.05 \& \mathrm{n}=$ sample size, sample size $(n)=\mathrm{N} / 1+\mathrm{Ne} 2=566 / 1+566(0.05), 2=234$.
\end{abstract}

Main Findings: The results of the study revealed that the significant and positive association among the research variables, the significant impact of the predictors on the criterion variable, and the significant partial mediating role of the employee commitment in the relationship between the toxic leadership and employees' performance.

Applications of Study: The current study focuses on examining the role of toxic leadership on employee performance with mediating effect of employee commitment within the banking sector of KP, Pakistan. This study's significance lies in the banking sector, desiring to acquire sustainable competitive advantage through increased employee performance and employee commitment.

Novelty/Originality of Study: The expectation that organizational commitment can improve the relationship between toxic leadership and employee performance is missed to a certain extent in the educational context that is expected to offer a new contribution to an existing database of research.

Keywords: Toxic Leadership, Organizational Commitment, Organizational Performance, HEIs.

\section{INTRODUCTION}

The leaders are deemed crucial to an organization's success or failure. With rising economies and the need for a competitive advantage over the rivals, divisions of human resources within organizational frameworks have started designing unique programs to use effective leadership to empower workers in a meaningful way. The leadership debate clearly emphasizes that employee success and motivation are primarily bases on leadership quality (Uysal, 2019). Leadership is the authority or power of a person over employees under their command who are expected to perform their employment (Gilbert, Ruffino, Ivancevich \& Konopaske, 2012). The leaders can establish or transform values, traditions, attitudes, as well as assumptions to inspire or empower workers to work better (Saqib \& Arif, 2017). A leader is a person who is responsible for creating a safe atmosphere in which employees of an organization feel comfortable in carrying out their respective tasks provided by management (Mathieu, Neumann, Hare \& Babiak, 2014). In this connection, keeping in view the existing complex and uncertain situations, the efficiency and engagement of employees are some factors that are greatly affected by leadership positions (Hadadian \& Zarei, 2016).

To achieve higher effectiveness and productivity thereby reaching the predefined goals, organizations have no choice but to pay adequate attention to human resources (Reyhanoğlu \& Akın, 2016). The leaders in organizations remained significant due to their influence on the human resources and, subsequently, organizational survival and existence based upon the styles of leadership that the leaders adopt in the concerned organizations. Leadership is effective in influencing followers such that they perform pre-determined activities voluntarily and willingly consistent with the organizational objectives (Pelletier, 2010). Toxic leadership is a leadership style that negatively affects its members that is harmful to followers and the organization (Mathieu, Neumann, Hare \& Babiak, 2014). It is a leadership style in which repetitive and systematic behaviors on leader part, supervisor and employer, threaten legitimate interests of organization by creating obstacles to the achievement of fulfillment and goals of the depletion/duties of organizational resources and decrease employee satisfaction, motivation, and effectiveness (Dobbs, 2014). This leadership style is a subcategory of unethical leadership that can lead to unethical behaviors on part of employees (Lašáková \& Remišová, 2015). Employee 
performance is the sum of measurable happenings that an employee or organizations achieves by adding value to the organization.

Similar to other sectors, leadership has an influential impact on the banking sector as well. The employees within the organization get highly motivated and show active participation when their organization provides them with a leadership type that gives them a highly supportive work environment (Gilbert, Ruffino, Ivancevich \& Konopaske, 2012). Besides, employee performance is improved through a strong sense of participation transferred within employees by leadership and develops a healthy organizational culture that enhances employees' commitment to work in a better way, which assists in adding value to the organization (Mathieu, Neumann, Hare \& Babiak, 2014). However, employee commitment is defined as the strong involvement of individual employees within their work, resulting in high employee recognition within an organization. In this regard, organizational behavior, employee performance, and employee commitment influence by the leadership in concerned organizations (Matos, Neill \& Lei, 2018). The researchers in the past have worked on explaining leadership roles in influencing employee performance and employee commitment in different contexts with different outcomes (Mehta \& Maheshwari, 2019). In contrast, there is not much research conducted regarding toxic leadership and its influence over employees' performance and commitment and this study is an effort to examine the desired relationships.

\section{PROBLEM STATEMENT}

Employee performance and employee commitment have been the most significant management issues (Tepper, Duffy, Henle, \& Lambert, 2016). It has been very costly for both employees and employers not to understand the leaderemployee relationship's importance. Lower organizational performance has to be experienced by business firms due to inappropriate employee commitment and performance. Failure to have an effective and transformational leader within an organization to motivate employees to work to their potential causes problems for both the employer and organization. They have to face critical loss both in form of knowledge and monetary aspects. Encouraging employees for a more extended period and motivating them to work to their full potential have been the most prominent challenges organizations have faced worldwide in the 21 st century. Numerous researchers have also explained that a leader's role is crucial for business firms to ensure their employees' high productivity and commitment to accomplish organizational objectives. However, business management has been using different leadership types for motivating their talented employees to improve their productivity and dedication. The majority of the research work was done on leadership's impact on employee performance and commitment.

\section{RESEARCH OBJECTIVES}

Based on the research problem, the primary aim of this research study is related to examine the relationships among research variables as extracted from the main theme of the study under consideration.

1. To find out the relationship between toxic leadership, employee performance, and employee commitment in the banking sector of KP, Pakistan.

2. To identify the impact of Predictors (toxic leadership and employee commitment) on employee performance.

3. To identify the role of employee commitment in influencing the relationship between toxic leadership and employee performance.

\section{SIGNIFICANCE OF STUDY}

1. The current study emphasized examining the role of toxic leadership on employee performance with the mediating effect of the employee commitment within the banking sector of KP, Pakistan.

2. This study's significance lies in the banking sector, desiring to acquire sustainable competitive advantage through increased employee performance and employee commitment. The findings of this study will clarify the influence of toxic leadership on employee performance and employee commitment.

3. This study will also provide logical evidence for Pakistan's banking sector regarding understanding toxic leadership and its influence on employee performance and commitment.

4. This study will significantly help stakeholders of the ser banking vice sector of Pakistan to understand toxic leadership's role in influencing employee performance and employee commitment.

5. It will prove crucial research for banking sector management to understand the relationship between variables. Hence, this research will show its significance in assisting the research students in increasing their literature knowledge.

\section{LITERATURE REVIEW}

When it comes to Pakistan's banking sector, leadership and human resource management have a vast scope. The economy of Pakistan has been getting stronger with every passing day as the multiple industrial sectors, including the banking sector, have been making a decisive contribution towards strengthening the country's economy. Organizational leadership has been an ongoing debate worldwide, as it has proved its importance in most parts of the world. Similarly, 
corporate leadership has immense significance in Pakistan's banking sector (Meyer, Stanley \& Parfyonova, 2012). Researchers in the past have worked on explaining the impact that leadership has on employee performance and commitment levels. Likewise, toxic leadership affects employee performance and employee commitment within Pakistan's banking sector. Like other sectors, firms working within the banking sector of Pakistan have been focusing on introducing an effective leader to motivate the employees to work to their revolutionary potential and help organizations accomplish their goals and objectives. Firms associated with the banking sector of Pakistan is developing a strengthened relationship with the employees through their leadership to increase employees' productivity. Effective leadership has to be useful within many industries of Pakistan, including the banking sector.

Still, there is a vast scope within the banking sector for implementing effective leadership. Most business firms are unaware that toxic leadership is not good enough to motivate employees to perform effectively (Hameed \& Waheed, 2011). In this era of globalization, Pakistan is amongst the developing economies of the world. It has been contributing positively through the industrial sectors to make its name in the industrial world. Effective leadership is vital to bring improvements within the banking sector, as business firms need to understand toxic leadership's negative influence over employees' productivity. Business firms associated with the banking sector might build and maintain their competitive advantage due to a better understanding and leadership implementation (Gilbert, Ruffino, Ivancevich \& Konopaske, 2012). The banking sector of Pakistan is amongst the sectors increasing with the advancement in technology and communication. While discussing the banking sector, leadership is the view as a front-office function that mostly pushes service orders and encourages employees to work to their potential (Stouten, Dijke \& De Cremer, 2012). In this regard, the banking sector, like other business sectors, has to take the initiative to implement efficient and charismatic leadership, which will be highly effective in raising the willingness and level of satisfaction of employees to inspire them to work hard and achieve their job-related objectives.

\section{TOXIC LEADERSHIP}

Toxic leadership refers to a process in which leaders, by dint of their destructive behavior or dysfunctional personal characteristics, inflict severe and enduring harm on their followers, their organizations, and non-followers alike. Defining toxic leaders can prove irritating, at best, since one individual toxic leader is another's heroic savior, given that context, history, and perspective weigh heavily in such judgments. A multidimensional framework is required to capture toxic leadership's complexity (Hadadian \& Zarei, 2016). Based on such a multifaceted structure, the types of harmful conduct in which they participate are clarified, the degree of severity of their toxicity, deliberate of toxic leaders, the types of unstable personal properties influencing their behavior and decisions (Mathieu, Neumann, Hare \& Babiak, 2014). About the intentions, those leaders who deliberately injure others/enhance themselves at others' expense about intentionally toxic. Such toxic leaders are opposed to the unintentional toxic leaders performing reckless or careless actions causes adverse effects (Lašáková \& Remišová, 2015). For complication of matters, each toxic leader does not have dysfunctional characterological mechanisms, similar destructive behaviors, and the same kind of toxicity, even in similar situations. Some toxic leaders may work and behave similarly in similar conditions, whereas most do not have any similarity between them in terms of toxicity (Rosenbach, 2018).

Based on different situations, the degree and extent of adverse effects of toxic leadership may vary. Various toxic leaders have distinguished degrees of toxicity, dysfunctional personal qualities, and destructive behavior when compared. Similarly, consequences and adverse effects of toxic actions and decision is different (Schyns \& Schilling, 2013). Followers tend to experience the charm of toxic leaders initially, soon followed by manipulation, mistreatment, undermining, and engaging with destructive behaviors. A toxic leader is an individual who engages with the followers through different actions (Shields et al., 2015). Leaving the followers (sometimes non-followers) worse off than found them by deliberately terrorizing, torturing, imprisoning, incapacitating, disenfranchising, demoralizing, intimidating and marginalizing, seducing, demeaning, undermining, or killing them (Pelletier, 2010). Toxic leadership is equally dependent on followers, and quite a few believe it still exists (Gilbert, Ruffino, Ivancevich \& Konopaske, 2012). In this regard, why so many followers agree that they often prefer to, and even now by promoting non-toxic leaders to build toxic online leaders, they need to examine three forces: psychosocial forces are resulting from contact between the person and his or her social environment, external forces and internal forces.

\section{EMPLOYEES' COMMITMENT}

Employee commitment is a state in which an employee is satisfied with the company and willing to display complete dedication and work towards their potential during work. The employees' commitment is the involvement of individuals within the organization and work-related activities to play a significant role in accomplishing its goals and objectives (Burke, 2017). Higher employee commitment reflects that the employee is delighted with his job and organization and makes higher productivity for the organization. In accord to (Reed, 2015), to organize employees is considered to be an employee's ability to portray a substantial desire and an explicit trust in the goals, an estimate of organization and what they believe to be a stable and precise organization, ability to perceive the organization. Boddy and Croft (2016) suggest that an employee's organizational commitment is the relationship between individual and organization and recognition of quality, destination, and goals, just as workers are eager to help the organization attain organizational respect. Mehta and Maheshwari (2013) study that these employees' commitment is a framework of thinking. The decisive impulse to organize employees is to maintain the long-lasting individual in a particular organization. This organization has the 
flexibility to build a large number of guarantees and efforts and has firm confidence in its quality, goals, and recognition of the organization's interests. Employee commitment highlights an employee's wish to stay associated with the organization for a very long time.

Besides, this study has explained the difference between employee commitment and organizational commitment. Mathieu, Neumann, Hare, and Babiak (2014) have overwhelmed the academic field of employee commitment. Their survey found that employee commitment can be broken down into three essential parts: specific standardization commitments, emotional commitments, and duration commitments. In this way, the exploration document will examine employee commitment. The study (Meyer, Stanley \& Parfyonova, 2012) has revealed that people management practices effectively influence employee performance. The more comprehensive effort and vitality of the organization's responsible person are like the miracle of embracing the excellent work practices that are also considered high contributions or high association work practices (Mathieu et al., 2014). Furthermore, Hameed and Waheed (2011) highlighted employee commitment as the complete devotion of employees towards the work and one's willingness to work to full potential for the organization. There is an expanding model in which organizations are actively promoting commitments between employees to benefit from subsequent employee performance, just as the employee turnover has declined. Despite this, some of the meaning of employee commitment has surfaced from different numbers (Mowday, Porter \& Steers, 2013). From different definitions, employee commitment can be attributed to the connection between individuals and work, just like the beliefs in work goals, through the great effort to achieve organizational goals as a vital part of organizations.

\section{EMPLOYEE PERFORMANCE}

Employee performance is defined as the sum of an employee's accomplishments. Employee performance consists of employees' behaviors and actions, which help an employee towards measurable achievements and adds value to the organization. According to Boddy and Croft 2016), the concept of employee success has taken to another level by incorporating value; as authors say, the expense of employees' acts and behavior in the workplace must be smaller than the value/worth of their accomplishment. The management improves employee performance by building employees' skills and abilities to raise their achievement and competence (Matos, O'Neill \& Lei, 2018). Employees who emphasize performance orientation tend to have fixed commands as they tend to express their competencies rather than improve their abilities. Such employees give their best to get impressive feedback from others relative to work performed (Schyns \& Schilling, 2013). In this connection, individual performance depends on motivation, willingness, and knowledge. The previous research also highlights that leaders can regulate the employees' performance.

The employees that have are performance-oriented tend to show less interest in the challenging tasks, as they focus more on performing tasks that are easily achievable and which guarantees success. In addition to that, they do not try new things to innovate and modify their abilities. Instead, they perform duties that ensure their high performance and reduces the chances of negative evaluations and performance damage (Mowday et al., 2013). Contrary to that, the employees who are learning-oriented believe in discovering new things to improve their skills and capabilities and perform their job (Matos, O'Neill \& Lei, 2018). Employees who are learning-oriented emphasize improving their past performance by applying new approaches, which will help them learn from errors committed in past and improve their performance (Pelletier, 2010). By implementing this approach, the employees improve their skills, abilities, and capabilities, enabling them to perform their duties and tasks more comprehensively (Rosenbach, 2018). The performance of employees is vital for structure potency and competitive advantage. The leaders promote the employees' self-esteem, and with passion and enthusiasm, they trigger a positive attitude towards the work of the employees.

Employees judge their employee performances based on their assessment and the information they get from other workplace employees. Consequently, employees tend to make adjustments to their actions and behaviors based on others' feedback. It has been explained that an individual's performance at the workplace has been a significant factor for influencing behaviors, actions, goals, choices, efforts, and reactions (Stouten, Van Dijke \& De Cremer, 2012). Moreover, employee performance is an indication of an individual's capability at the workplace. Referring to the study of (Ashakanasy \& Humphrey, 2011), employees' behaviors and attitudes have been effectively explained with goal orientation theory. This theory is a way of proposing persuasion of two kinds of goal orientation by the individuals that are categorized as the learning goals and performance goals. Concerning the study of (Shields et al., 2015), it has been evident that organizational researchers have focused on improving employee performance. According to past studies, it has been cleared that employee performance cannot be considered a single unified construct. Employee performance must be recognized as a multidimensional construct comprising multiple types of behavior. In past studies, selfevaluations have showing to be a crucial source of helping a person observe employees' success.

\section{RESEARCH HYPOTHESES}

$\mathbf{H}_{\mathbf{1}}$ : There is a significant negative relationship between toxic leadership, employee performance, and employee commitment in the banking sector of KP, Pakistan.

$\mathbf{H}_{2}$ : Predictors have a significant impact on employee performance in the banking sector of KP, Pakistan. 
$\mathbf{H}_{3}$ : Employee commitment plays its role as a mediator between Toxic leadership and employee performance in the banking sector of KP, Pakistan.

\section{RESEARCH METHODOLOGY}

The research design is defined by (Sreejesh, Mohapatra, \& Anusree, 2014) as the strategy to test theory". Other researchers describe a standard used to evaluate business research and evaluate the framework that will support the research questions (Bell \& Kozlowski, 2018). In this study, the cross-sectional design was used to examine the existing realities to explore the new as well as innovative information.

\section{Nature \& setting of the study}

The study's nature is casual targeted and finds the impact of the toxic leadership on employee performance with the mediating effect of the employee commitment. It is a field study by filling questioners from the employees of the banking sector of KP during work hours to explore the relationships among the research variables under consideration in the context of the banking sector in Pakistan.

\section{Unit of analysis \& time horizon}

According to Khan (2019), the Unit of analysis is "any individuals analyzed by the researcher." Each member in the organization is a unit, and one element of the population is called a unit of analysis. The data will collect in the time frame of approximately two months and collect in one time period. Consequently, the data was cross-sectional that aimed at exploring the existing and leading realities in the native environment.

\section{Population of study}

The Population is the aggregate of all elements on which this study's findings were generalized. It is a collection of all the details we are studying and about which we are trying to conclude (Cohen \& Cohen 1975). In this connection, the population of the current study comprised all the employees working in the selected banks wherein the details have been provided in the below-mentioned table.

Table 1: Details of Population

\begin{tabular}{lcc}
\hline Name of Banks & No. of Branches in Districts & No. of Employees \\
\hline National Bank of Pakistan & 32 & 175 \\
\hline Bank of Khyber & 07 & 35 \\
\hline Allied Bank Ltd & 10 & 123 \\
\hline Askari Bank Ltd & 10 & 86 \\
\hline Bank Al-Falah & 17 & 92 \\
\hline Muslim Commercial Bank & 09 & 55 \\
\hline
\end{tabular}

Sources: (www. Sbp.org.pk), (www.google.com.pk), concerned Bank

\section{Sampling \& sample}

A sample survey is selected of respondents and administers a standardized questionnaire (Sekaran \& Bougi, 2010). Sampling is selecting a sufficient number of elements from the Population. By studying the sample and understanding sample subjects' properties or characteristics, it would be possible to generalize properties or features to the population elements (Soper, 2014). The present study sample of 234 employees (OG-III, OG-II, OG-I, AVP) of both Public/Private sector banks was taken randomly as a sample. To compute the sample size using Yamane (1967) formula for selecting a sample from a "Finite Population": N = Population (566); Level of Significance "e" = 0.05 \& n = Sample size; Sample size $(n)=\mathrm{N} / 1+\mathrm{Ne} 2=566 / 1+566(0.05)^{2}=234$. Therefore, a total of 234 questionnaires were distributed among which 220 were recollected and used for statistical procedure to examine the relationships.

\section{Data collection methods}

The banking data was obtained from all levels of managers. The data was collected via a 5-point Likert scale through a structured questionnaire. In this regard, managers working at other banks are considering the data collection in the current study.

\section{Measurement}

Table 2: Instruments of Study

\begin{tabular}{lll}
\hline Variables & Source & Items \\
\hline Toxic Leadership & Schmidt (2008) & 06 \\
\hline Employee Performance & Salanova, Agut \& Pier (2005) & 06 \\
\hline Employee Commitment & (Meyer \& Allen, 1991; 1997) & 06 \\
\hline
\end{tabular}




\section{Data analysis tools}

The SPSS (21.0) version will use for reliability, descriptive, frequency, correlation, regression, and mediation analysis. The reliability test will test the consistency of the data. A correlation test will test the relationship between variables, and Regression analysis is used to check the variables' dependency. For mediation analysis, the researcher used the (Hayes, 2013) procedure to examine the mediating role of organizational commitment in connecting toxic leadership and employees' performance.

\section{FINDINGS \& DISCUSSION}

The statistical relationships have been offered in this section that aimed at attaining objectives as aligned with hypotheses of study in order to reach the study conclusion. The procedure included correlation, regression, and mediation with the aim to examine and find the answers to research hypotheses. Likewise, the results have been validated through the results of existing research studies.

Table 3: Correlation Analysis

\begin{tabular}{llcc}
\hline & & Toxic Leadership & Organizational Commitment \\
\hline Organizational Commitment & Pearson Correlation & $-.665^{* * *}$ & \\
\cline { 2 - 4 } & Sig. (2-tailed) & .000 & \\
\cline { 2 - 4 } & $\mathrm{N}$ & 220 & $.721^{* *}$ \\
\hline \multirow{2}{*}{ Employees Performance } & Pearson Correlation & $-.457^{* * *}$ & .000 \\
\cline { 2 - 4 } & Sig. (2-tailed) & .000 & 220 \\
\cline { 2 - 4 } & $\mathrm{N}$ & 220 & \\
\hline$* *$ Correlation is significant at the 0.01 level (2-tailed). & & \\
\hline
\end{tabular}

The association was hypothesized through $\mathrm{H}_{1}$, wherein correlation was used to examine the association among toxic leadership, employees' commitment, and performance. The results revealed the significant association of predicting variables with employees' performance like the toxic leadership (-.457 \& .000), organizational commitment (.721 \& $.000)$, and the organizational commitment and toxic leadership (-665 \& .000). Therefore, from the results, the hypothesis about the association is accepted. The results of this study are similar to a certain extent to the results of previous studies (Mehta \& Maheshwari, 2019; Saqib \& Arif, 2017). Thus, the present study provides support through existing research studies as conducted in different contexts.

Table 4: Regression Analysis

\begin{tabular}{rrrrrrr}
\hline Model & $\mathbf{R}$ & $\mathbf{R}^{2}$ & Adjusted R & SEE & F & Sig. \\
\hline 1 & $.722^{\mathrm{a}}$ & .521 & .517 & .31570 & 118.014 & $.000^{\mathrm{b}}$ \\
\hline
\end{tabular}

Table 5: Regression Analysis

\begin{tabular}{|c|c|c|c|c|}
\hline Model & Unstandardized Coefficients & Standardized Coefficients & $\mathbf{t}$ & Sig. \\
\hline & Std. Error & Beta & & \\
\hline $1 \quad$ (Constant) & 1.509 & & 7.343 & .000 \\
\hline Toxic Leadership & .022 & .039 & .624 & .533 \\
\hline Organizational Commitment & .035 & .747 & 11.885 & .000 \\
\hline \multicolumn{5}{|c|}{ a. Predictors: Toxic Leadership \& Organizational Commitment } \\
\hline \multicolumn{2}{|c|}{ b. Dependent Variable: Employees Performance } & & & \\
\hline
\end{tabular}

The influence of predictor (toxic leadership and organizational commitment) on employees' performance was hypothesized through $\mathrm{H}_{2}$ by using regression procedure. The regression shows that predictors have a significant impact on the criterion variable wherein $52 \%$ variance is evident. Similarly, the coefficient of regression revealed significant information wherein the toxic leadership remained insignificant in the regression procedure (.022 \& 533) while organizational commitment remained significant (.419\& .000). Therefore, from regression outcomes, the $\mathrm{H}_{2}$ is thus partially accepted. The results have been validated through previous studies results (Kiliç \& Günsel, 2019; Baloyi, 2020;

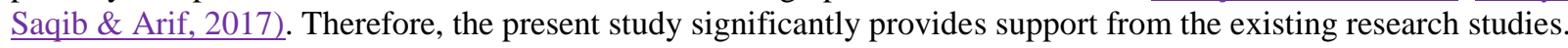

Table 6: Mediation Analysis

\begin{tabular}{|c|c|c|c|c|c|c|}
\hline DV & IV & $\mathbf{R}$ & $\mathbf{R}^{2}$ & $\beta$ & $\mathbf{F}$ & $\mathbf{p}$ \\
\hline \multicolumn{7}{|l|}{ Mediation Path (a) } \\
\hline Organizational Commitment & Toxic Leadership & 6646 & .4416 & -.6744 & $172.4244 \cdot 13.1310$ & .0000 \\
\hline \multicolumn{7}{|l|}{ Mediation Paths (b \& ć) } \\
\hline \multirow[t]{2}{*}{ Employees' Performance } & Toxic Leadership & .7218 & .5210 & .0223 & 118.0143 .6240 & .0000 \\
\hline & Organizational Commitment & & & .4189 & $118.0143 \quad 11.8852$ & .0000 \\
\hline
\end{tabular}




\begin{tabular}{llllllll}
\hline Employees' Performance & Toxic Leadership & .4574 & .2092 & -.2602 & 57.6676 & -7.5939 & .5333 \\
\hline
\end{tabular}

The mediating role of organizational commitment in linking toxic leadership and the performance of employees was predicted and hypothesized through $\mathrm{H}_{3}$. Results provide significant information about the full mediation role of organizational commitment. The table above presented the findings regarding the mediation procedure wherein the model fitness like the goodness of fit is found significant $\mathrm{F}=172.4244, \mathrm{p}<0.01$ which indicate that the regression equation is best fit for the current analysis. $\mathrm{R}^{2}$ is 0.44 i.e., $44 \%$ change is explained by two factors on the employees' performance. Furthermore, results exposed that the beta value of the predictors $\beta=0.02, p<0.01$, which means that oneunit alteration in the employee performance could bring additional variation in performance. Also, $\beta=0.42, p>0.05$ indicates that 1-unit alteration in organizational commitment may bring $4.2 \%$ variation in employees' performance. Third $\beta=-0.26, p<0.01$ indicates a $2.6 \%$ change in employees' performance while $\beta=0.021$ has resulted as the outcome. Consequently, from the results, the $\mathrm{H}_{3}$ is accepted as organizational commitment fully mediated relationship between toxic leadership and employee performance in the context of the banking sector in developing countries like Pakistan. The results of the study have been validated thereby providing support from existing research studies (Mohamed, Nasser, Jabeen, \& Rawas, 2018; Donkor, Zhou \& Sekyere, 2021; Paltu \& Brouwers, 2020). Consequently, the present study provides significant support and backing to the results from existing research studies.

\section{CONCLUSION}

The present study explored toxic leadership in connection to employees' performance with mediating role of organizational commitment. The results of the study revealed the significant and varied association amid toxic leadership, organizational commitment, and employee performance and thus the assumption about the association was decided as accepted. Similarly, the impact of toxic leadership and organizational commitment as predictors toward employees' performance was examined through regression wherein the results revealed the significant impact wherein the toxic leadership has negative while organizational commitment has a positive impact on employees' performance. Likewise, the mediating role of organizational commitment was thus examined which shows that commitment fully mediated the relationship between toxic leadership and employees' performance. Consequently, the present study provides significant information about the relationship among the variables that are expected to provide the significant as well as leading contribution to existing database ok knowledge. The study is also expected to provide significant information to the baking sector about the application of toxic leadership wherein the banks can get practical guidelines about the application of leadership in the banking sector. Thus, from the results, some recommendations have been extracted and offered to the banking sector for the application of toxic leadership, organizational commitment, and the employees' performance.

\section{RECOMMENDATIONS \& IMPLICATIONS}

1. The toxic leadership is certain varied consequences for the organizations and therefore, the management of the banking sector is suggested to carefully used this leadership style in order to ensure the desired efforts and performance from the concerned employees in concerned banks.

2. Organizational commitment is a vital predictor for various desired outcomes and thus the banking sector is required to adopt the strategies that are helpful for improving the employees' undaunted affiliations with the concerned banks that further leads to higher performances.

3. The performance is the significant predictor towards the development and success of the organizations; therefore, the management of the banking sector is required to cater to the needs and desires of the employees to inspire them towards higher performances in the concerned banks.

4. The study provides significant results that could be applicable in the banking sector as well as other sectors to extract suitable guidelines as proposed in this study through the existing literature as well as empirical investigations as analyzed from a field study in the present research study.

\section{FUTURE RESEARCH \& LIMITATION}

1. Future researchers may use the methodologic approach used in this research for their studies conducted in different as well as in similar contexts to get the desired outcomes in a particular context.

2. The future researcher is advised to apply certain other mediators and moderators in linking toxic leadership and employees' performance to get desired outcomes and to contribute to the existing database.

3. Future researchers are suggested to examine and research these phenomena in the other context to compare these results with the results of this study in order to compare the common and different parameters.

4. The study was limited only to the banking sector; however, the same theoretical framework can be tested in another context to the extent of the boundaries of research to the broader level to examine the phenomena from different dimensions. 


\section{AUTHORS' CONTRIBUTION}

Muhammad Rehman is the principal contributor by providing a unique conceptual theme of study. Dr. Hamid Khan and Dr. Sajjad Ahmad Jan did the statistical procedure and analysis via SPSS. Dr. Aziz Javad and Dr. Aman Ullah Khattak arranged the drafting and revision of the manuscript.

\section{REFERENCES}

1. Baloyi, G. T. (2020). Toxicity of leadership and its impact on employees: Exploring the dynamics of leadership in an academic setting. HTS Teologiese Studies / Theological Studies, 76(2), 8. https://doi.org/10.4102/h ts.v76i2.5949

2. Bell, B. S., \& Kozlowski, W. J. (2018). Goal orientation and ability: interactive effects on self-efficacy, performance, and knowledge. Journal of Applied Psychology, 87(3) 497-505. https://doi.org/10.1037/0021$\underline{9010.87 .3 .497}$

3. Boddy, C. R., \& Croft, R. (2016). Marketing in a time of toxic leadership. Qualitative Market Research: An International Journal, 19(1), 44-64. https://doi.org/10.1108/QMR-04-2015-0030

4. Burke, R. J. (2017). The Toxic leaders: Exploring the dark side. The Effective Executive, 20(1), 10.

5. Chawla, D., \& Sodhi, N. (2011). Research methodology: Concepts and cases. Vikas Publishing House.

6. Cogliser, C., Schriesheim, C. A., Scandura, T. A., \& Gardner, W. L. (2009). Balance in leader and follower perceptions of leader-member exchange: Relationships with performance and work attitudes. The Leadership Quarterly, 20(3), 452-465. https://doi.org/10.1016/j.leaqua.2009.03.010

7. Dobbs, J. M. (2014). The relationship between perceived toxic leadership styles, leader effectiveness, and organizational cynicism. Available from ProQuest Dissertations and Theses database. (UMI No. 3575052). https://www.worldcat.org/libraries/65572

8. Donkor, F., Zhou, D., \& Sekyere, I. (2021). The Mediating Effects of Organizational Commitment on Leadership Styles and Employee Performance in SOEs in Ghana: A Structural Equation Modeling Analysis. SAGE Open, April-June (2021), 1-17. https://doi.org/10.1177/21582440211008894

9. Erickson, A., Shaw, B., Murray, J., \& Branch, S. (2015). Destructive Leadership. Organizational Dynamics, 4(44), 266-272. https://doi.org/10.1016/j.orgdyn.2015.09.003

10. Flick, U. (2015). Introducing research methodology: A beginner's guide to doing a research project. Sage.

11. Gilbert, J. A., Carr-Ruffino, N., Ivancevich, J. M., \& Konopaske, R. (2012). Toxic versus cooperative behaviors at work: the role of organizational culture and leadership in creating community-centered organizations. International Journal of Leadership Studies, 7(1), 29-47.

12. Hadadian, Z., \& Zarei, J. (2016). Relationship between toxic leadership and job stress of knowledge workers. Studies in Business and Economics, 11(3), 84-89. https://doi.org/10.1515/sbe-2016-0037

13. Hameed, A., \& Waheed, A. (2011). Employee development and its effect on employee performance a conceptual framework. International journal of business and social science, 2(13).

14. Hayes, A. F. (2013). An Introduction to Mediation, Moderation and conditional process Analysis. New York: The Guilford Press.

15. Iqbal, N., Anwar, S., \& Haider, N. (2015). Effect of leadership style on employee performance. Arabian Journal of Business and Management Review, 5(5), 1-6.

16. Kant, L., Skogstad, A., Torsheim, T., \& Einarsen, S. (2013). Beware the angry leader: Trait anger and trait anxiety as predictors of petty tyranny. The Leadership Quarterly, 24(1), 106-124. https://doi.org/10.1016/j.lea qua.2012.08.005

17. Kiliç, M., \& Günsel, A. (2019). The Dark Side of the Leadership: The Effects of Toxic Leaders on Employees. European Journal of Social Sciences, 2(2), 51-56. https://doi.org/10.26417/ejss-2019.v2i2-64

18. Lam, M., O'Donnell, M., \& Robertson, D. (2015). Achieving employee commitment for continuous improvement initiatives. International Journal of Operations \& Production Management, 35(2), 201-215. https://doi.org/10.1108/IJOPM-03-2013-0134

19. Lašáková, A., \& Remišová, A. (2015). Unethical Leadership: Current Theoretical Trends and Conceptualization. Procedia Economics and Finance, 34, 319-328. https://doi.org/10.1016/S2212$\underline{5671(15) 01636-6}$

20. Mathieu, C., Neumann, C. S., Hare, R. D., \& Babiak, P. (2014). A dark side of Leadership: Corporate psychopathy and its influence on the employee well-being and job satisfaction. Personality and Individual Differences, 59, 83-88. https://doi.org/10.1016/j.paid.2013.11.010

21. Matos, K., O'Neill, O., \& Lei, X. (2018). Toxic leadership and the masculinity contest culture: How "win or die" cultures breed abusive leadership. Journal of Social Issues, 74(3), 500-528. https://doi.org/10.111 $1 /$ josi. 12284

22. Mehta, S., \& Maheshwari, G. C. (2019). Consequence of Toxic Leadership on Employee Job Satisfaction and Organizational Commitment. Journal of Contemporary Management Research, 8(2). 1-23.

23. Meyer, J. P., Stanley, L. J., \& Parfyonova, N. M. (2012). Employee commitment in context: The nature and implication of commitment profiles. Journal of Vocational Behavior, 80(1), 1-16. https://doi.org/10.1016/ j.jvb.2011.07.002 
24. Mohamed, B., Nasser, A., Jabeen, F., \& Rawas, A. (2018). Toxic leadership and organizational citizenship behavior: a mediation effect of followers' trust and commitment in the middle east. International Journal of Business and Society, 19(3), 793-815.

25. Mowday, R. T., Porter, L. W., \& Steers, R. M. (2013). Employee-organization linkages: The psychology of commitment, absenteeism, and turnover. Academic Press.

26. Nefai, W. A. (2019). The Impact of Toxic Leadership on Job Attitudes A Study on Teaching Hospitals in Egypt, Case Studies Journal, 8(2), 45-58.

27. Ofori, G. (2009). Ethical Leadership: Examining the relationships with full range leadership model, employee outcomes, and organizational culture. Journal of Business Ethics, 90(4), 533. https://doi.org/10.1007/s10551009-0059-3

28. Paltu, A., \& Brouwers, M. (2020). Toxic leadership: Effects on job satisfaction, commitment, turnover intention and organizational culture within the South African manufacturing industry. SA Journal of Human Resource Management, 18(0), a1338. https://doi.org/10.4102/sajhrm.v18i0.1338

29. Pelletier, K. L. (2010). Leader toxicity: An empirical investigation of toxic behavior and rhetoric. Leadership, 6(4), 373-389. https://doi.org/10.1177/1742715010379308

30. Reed, G. E. (2015). The Tarnished: toxic leadership in the US military. U of the Nebraska Press. Publisher: University of Nebraska Press. https://doi.org/10.2307/j.ctt1d988m9

31. Reyhanoğlu, M., \& Akın, Ö. (2016). Toksik Liderlik Örgütsel Sağlığı Olumsuz Yönde Tetikler mi? İnsan ve Toplum Bilimleri Araştırmalarl Dergisi, 5(3), 442-459. https://doi.org/10.15869/itobiad.41373

32. Salanova, M., Agut, S. \& Peiró, J.M. (2005). Linking Organizational Resources and Work Engagement to Employee Performance and Customer Loyalty: The Mediation of Service Climate. Journal of Applied Psychology, 90, 1217-1227. https://doi.org/10.1037/0021-9010.90.6.1217

33. Saqib, A., \& Arif, M. (2017). Employee Silence as a Mediator in the Relationship between Toxic Leadership Behavior and Organizational Performance. Journal of Managerial Sciences, 11(3), 83-104.

34. Schyns, B., \& Schilling, J. (2013). How bad are the effects of bad leaders? A meta-analysis of destructive leadership and its outcomes. The Leadership Quarterly,24(1), 138-158. https://doi.org/10.1016/j.lea qua.2012.09.001

35. Shezan, S., Al-Mamoon, A., \& Ping, H. (2018). Performance investigation of an advanced hybrid renewable energy system in Indonesia. Environmental Progress \& Sustainable Energy, 37(4), 1424-1432. https://doi.org/ 10.1002/ep. 12790

36. Shields, J., Brown, M., Kaine, S., Dolle-Samuel, C., North-Samardzic, A., McLean, P., \& Plimmer, G. (2015). Managing employee performance \& reward: Concepts, practices, strategies. Cambridge University Press. https://doi.org/10.1017/CBO9781139197120

37. Sreejesh, S., Mohapatra, S., \& Anusree, M. R. (2014). Business Research Reports. In Business Research Methods (pp. 261-277). Springer International Publishing. https://doi.org/10.1007/978-3-319-00539-3_12

38. Stouten, J., Van Dijke, M., \& De Cremer, D. (2012). Ethical leadership. An overview and future perspectives. Journal of Personnel Psychology, 11(1), 1-6. https://doi.org/10.1027/1866-5888/a000059

39. Tepper, B. J., Du_y, M. K., Henle, C. A., \& Lambert, L. S. (2016). Procedural injustice, victim precipitation, and abusive supervision. Personnel Psychology, 59(1), 101-123. https://doi.org/10.1111/j.17446570.2006.00725.x

40. Toor, S. U. R., \& Ogunlana, S. (2009). Ineffective Leadership: Investigating the negative attributes of leaders and organizational neutralizers. Engineering, Construction and Architectural Management, 16(3), 254-272. https://doi.org/10.1108/09699980910951663

41. Uysal, H. T. (2019). The Mediation Role of Toxic Leadership in the Effect of Job Stress on Job Satisfaction, International Journal of Business, 24(1), 55-73.

42. Yamane, Taro. (1967). Statistics: An Introductory Analysis (2nd Edition). New York: Harper and Row. 